\title{
Formulation of Polymeric Multicomponent Systems Containing Cardiovascular APIs
}

\begin{abstract}
FAWZIA SHA'AT ${ }^{1,2 *}$, RAMONA DANIELA PAVALOIU ${ }^{1}$, DANIELA CRINA SALCEANU ${ }^{1}$, CRISTINA HLEVCA ${ }^{1}$, GHEORGHE NECHIFO R ${ }^{2 *}$
${ }^{1}$ National Institute for Chemical-Pharmaceutical Research\&Development - ICCF, Bucharest, 112 Vitan Av., 031299, Bucharest, Romania

${ }^{2}$ University Politehnica of Bucharest, Faculty of Applied Chemistry and Materials Science, 1-7 Gheorghe Polizu Str., 011061, Bucharest

The main aim of this study was to prepare and characterize polymeric nanoparticles containing two cardiovascular active pharmaceutical ingredients: valsartan (VAL) and amlodipine besylate (AML). Six formulations were evaluated with different ratios of AML:VAL:PLGA (1:16:17, 1:16:34, and 1:16:51) and different stirring speed (1200 and $2400 \mathrm{rpm})$. Encapsulation efficiency (EE, \%) and particle size analyses were performed to characterize and optimize the formulation. All loaded nanoparticles showed a high EE (\%), nano-size, negative $\xi$-potential and a high homogeneity.
\end{abstract}

Keywords: nanotechnology, cardiovascular drugs, drug delivery systems, medicinal chemistry.

Nowadays, nanotechnology represents the principal domain of interest in biomedicine, and therefore helps research community to improve and develop the technologies for the cardiovascular disease's treatment $[1,2]$. The current trend of the development of pharmaceutical industry is represented by super generic drugs. This kind of medication, which mostly represents delivery systems of APIs (Active Pharmaceutical Ingredients) focused on improving the APIs properties (pharmacokinetic properties) previously marketed in other pharmaceutical forms. These new formulations can successfully replace the generic products. In the cardiovascular treatment, super generics can improve solubility in aqueous media, for APIs, like: valsartan, irbesartan, nimodipine, carvediol, amlodipine besylate, etc.; several methods have been developed to dispose this disadvantage, such as the use of surfactants, lipids, permeation promoters, micronization, use of salts, cyclodextrines, nanoparticles and solid dispersions $[3,4]$. In contrast to studies that have very good results for a single API and its matrix, this work is geared toward the study of nano-systems that contain two APIs encapsulated simultaneously in a biodegradable polymer. In recentyears, nanoparticles (NPs) with polymeric matrix have been used due to the biodegradable property of the polymer, particularly those with a hydrophilic polymer such as PEG or PLGA, recognized as having a high circular distance and thus the ability to travel for a long time to a target organ, as a DNA transporter in gene therapy, and the ability to deliver proteins, peptides or genes $[5,6]$.

The main objective of this paper is to obtain and characterize the multicomponent systems on nanoscale, because in this way there are prerequisites for improvement the low solubility profile of the therapeutic agents, to reduce the frequency dosing and to increase the bioavailability of APIs with action in cardiovascular pathology. For this purpose, mixed APIs - an angiotensin II receptor antagonistdrug (valsartan) and a calcium channel blocker (amlodipine besylate) - and polymeric matrix were chosen suitable: polymer at different concentrations, stabilizer in a constant concentration, at two different stirring speed, in order to obtain I particle size and a good encaspsulation efficiency.

\section{Experimental part}

Materials and methods

Poly (D,L-lactide-co-glicolide) (PLGA, 50:50, $\mathrm{M}_{w}=$ 30,000 - 60,000 Da), amlodipine besylate (2- $(2$ aminoethoxy)-methyl]-4-(2-chlorophenyl)-1,4-dihydro-6methyl-3,5-pyridinedicarboxylic acid 3-ethyl 5-methyl ester benzene sulfonate) with $M_{w}=567.05 \mathrm{~g} / \mathrm{mol}$, valsartan ( $N$-(1-Oxopentyl)- $N$-[ [22-(2H-tetrazol-5-yl) [1,12-biphenyl]4-yl]methyl]-L-valine) with $M_{w}=435.51 \mathrm{~g} / \mathrm{mol}$ and Poloxamer 407, known as Pluronic F127 (poly(ethylene glycol)-block-poly(propylene glycol)-block-poly(ethylene glycol)) were obtained from Sigma Aldrich (USA). The water used for all experiments was distilled. All other chemicals were of analytical grade obtained from standard sources and used without further purification.

\section{Preparation of NPS}

NPs were prepared according to nanoprecipitation method $[7,8]$. PLGA at three different concentrations (17, $34,51 \mathrm{mg}$ ) was dissolved in acetone $(5 \mathrm{~mL})$, and both drugs were combined in a fixed-dose (AML:VAL - 1:16 $\mathrm{mg}$ ) in PLGA/acetone solution. Pluronic-F127 (10 mg) was dissolved in distilled water $(15 \mathrm{~mL})$. The organic phase was added dropwise into the aqueous phase solution and stirred magnetically at two different stirring speed (1200 and $2400 \mathrm{rpm}$ ) at room temperature $\left(25^{\circ} \mathrm{C}\right)$ until complete evaporation of the organic solvent (table 1 ). The final nanosuspension was centrifuged at $10000 \mathrm{rpm}$ for $30 \mathrm{~min}$ at $3^{\circ} \mathrm{C}$ to separate the drug polymeric aggregates and then it was filtered through $0.22 \mu \mathrm{m}$ Millex®filter membrane.

\section{Evaluation of drug encapsulation efficiency}

Encapsulation Efficiency ( $\mathrm{EE}, \%)$ was evaluated using the following equation (1) :

$E E(\%)=\frac{\text { Initial amount of APIs }- \text { Amountof APIs in supernatath }}{\text { Initial amount of APIs }} \times 100$

The percentage of encapsulated drugs was determined by using UV-Vis spectrophotometer at $365 \mathrm{~nm}$ for AML and $250 \mathrm{~nm}$ for VAL (JASCO V-630 Spectrophotometer, J asco International Co., Ltd., Japan).

\footnotetext{
*email: fawzya.shaat@gmail.com; doru.nechifor@yahoo.com
} 


\begin{tabular}{|c|c|c|c|c|c|c|c|c|c|}
\hline $\begin{array}{c}\text { Formulation } \\
\text { cod }\end{array}$ & $\begin{array}{c}\text { maML: } \\
\text { mVAL }(\mathrm{mg})\end{array}$ & $\begin{array}{l}\text { mPLGA } \\
(\mathbf{m g})\end{array}$ & $\begin{array}{l}\text { mF127 } \\
(\mathrm{mg})\end{array}$ & $\begin{array}{l}\mathrm{VCH}_{3}-\mathrm{CO}- \\
\mathrm{CH} 3(\mathrm{ml})\end{array}$ & $\begin{array}{l}V_{\mathrm{H} 2 \mathrm{O}} \\
(\mathrm{ml})\end{array}$ & $\begin{array}{c}\text { Drop rate } \\
(\mathrm{ml} / \mathrm{min})\end{array}$ & $\begin{array}{c}\text { Stirring } \\
\text { speed (rpm) }\end{array}$ & $\begin{array}{c}\text { Stirring } \\
\text { time } \\
\text { (min) }\end{array}$ & \\
\hline F1 & $1: 16$ & 17 & 10 & 5 & 15 & 0.5 & \multirow{3}{*}{1200} & \multirow{6}{*}{25} & \\
\hline F2 & $1: 16$ & 34 & 10 & 5 & 15 & 0.5 & & & $\begin{array}{l}\text { FORMULATION OF } \\
\text { POLYMERIC NPS }\end{array}$ \\
\hline F3 & $1: 16$ & 51 & 10 & 5 & 15 & 0.5 & & & $\begin{array}{l}\text { WITH AML-VAL } \\
\text { ENCAPSULATED }\end{array}$ \\
\hline F4 & $1: 16$ & 17 & 10 & 5 & 15 & 0.5 & \multirow{3}{*}{2400} & & \\
\hline F5 & $1: 16$ & 34 & 10 & 5 & 15 & 0.5 & & & \\
\hline F6 & $1: 16$ & 51 & 10 & 5 & 15 & 0.5 & & & \\
\hline
\end{tabular}

Measurement of particle size, polydispersity index and æpotential

Particle size, polydispersity index (PDI) and $\xi$-potential were determined by Dynamic Light Scattering (DLS Malvern Zetasizer, Malvern Instruments Ltd, UK) method. Particle size and PDI were measured on samples diluted with distilled water $(1: 80)$ at a scattering angle of $90^{\circ}$, a temperature of $25^{\circ} \mathrm{C}$, solvent refractive index of 1.458 and solvent viscosity of $0.8872 \mathrm{CP}$. For $\xi$-potential measurement, all analyses were performed on undiluted samples.

\section{Statistical analysis}

Values are represented as mean \pm standard deviation (SD) for three replicate samples. Differences were considered significant at $p<0.05$.

\section{Results and discussions}

Formulation and encapsulation efficiency of NPS

The developed formulation is intended to improve the drug solubility of the two selected APIs: amlodipine besylate (solubility $1.91099 \mathrm{~g} / \mathrm{L}$ (water, $32^{\circ} \mathrm{C}$ )) and valsartan (solubility $1.406 \mathrm{mg} / \mathrm{L}$ (water, $25^{\circ} \mathrm{C}$ ), solubility in methanol and ethanol). The fixed-dose combination (AML:VAL = 1:16 (mg)) was chosen based on Hypertension Clinical Guidelines [8-12]. Two parameters were varied: the concentration of PLGA (17, 34 and $51 \mathrm{mg}$ ) and the stirring speed (1200 and $2400 \mathrm{rpm}$ ). As showed in table 2, a strong relationship could be observed between PLGA concentration and the encapsulation efficiency.

All formulations (F1-F6) showed high EE (\%) for both APIs, ranged from $79.35 \pm 0.13 \%$ to $81.21 \pm 0.13 \%$ for VAL and from $59.90 \pm 0.12 \%$ to $67.58 \pm 0.11 \%$ for AML. Two parameters were varied, namely: PLGA concentration and stirring speed. Depending of which parameter was modified, the NPs have a different EE (\%) and size. Thus, at
$1200 \mathrm{rpm}$ and $2400 \mathrm{rpm}$ all formulations revealed a slightly increasing in $\mathrm{EE}(\%)$ with increasing concentration of polymeric matrix. By increasing the amount of PLGA (17, 34 and $51 \mathrm{mg}$ ), the nanoparticle suspension became more and more turbid. Also, as data literature has shown, PLGA can be processed into any size and shape and therefore can encapsulate substances of any size [13]. With the increased amount of PLGA, nanoparticles may encapsulate to a greater extent poorly-water soluble drugs, leading to a higher EE (\%) values. These values of EE (\%) could be due to the fact that higher amounts of polymer led to more viscous organic solutions. A higher concentration of PLGA leads to larger nanoparticles with a sufficient surface for drugs molecules to be entrapped. Also, an increased viscosity could block the drug's diffusion from the organic phase into the aqueous one, and therefore promote AML-VAL entrapment [14].

Contrariwise, comparing the formulations with same concentration of PLGA, but different stirring speed, it has shown in table 2 better EE (\%) for formulations in which the stirring speed was $2400 \mathrm{rpm}$ than those in which preparation was used a stirring speed of $1200 \mathrm{rpm}$. By increasing the stirring speed, the amount of AML-VAL entrapped slightly increased as well. Higher stirring speed causes smaller droplets and therefore the total surface area of the nanoparticles increase. This fact leads to an extra space for the polymer matrix to encapsulate more AMLVAL molecules; thereby the EE (\%) was slightly improved. These results were similar to those reported by Kheradmandnia S et al. [15].

\section{Characterization of PLGA NPS}

Mean particle size, PDI and $\xi$-potential were assessed for all the PLGA formulations with cardiovascular APIs encapsulated. The measured parameters are shown in

\begin{tabular}{|c|c|c|c|c|}
\hline $\begin{array}{c}\text { Formulation } \\
\text { code }\end{array}$ & $\begin{array}{c}\text { Mean particle size } \\
(\mathbf{n m})\end{array}$ & $\begin{array}{c}\zeta \text {-potential } \\
(\mathbf{m V})\end{array}$ & PDI & EE (\%) \\
\hline F1 & $158.4 \pm 1.15$ & $-13.46 \pm 0.31$ & $0.091 \pm 0.04$ & $\begin{array}{c}79.89 \pm 0.13 \text { for VAL } \\
65.35 \pm 0.11 \text { for AML }\end{array}$ \\
\hline F2 & $171.1 \pm 1.30$ & $-17.07 \pm 0.22$ & $0.048 \pm 0.03$ & $\begin{array}{c}80.03 \pm 0.10 \text { for VAL } \\
65.43 \pm 0.10 \text { for AML }\end{array}$ \\
\hline F3 & $204.1 \pm 1.34$ & $-21.34 \pm 0.21$ & $0.102 \pm 0.05$ & $\begin{array}{c}80.10 \pm 0.14 \text { for VAL } \\
67.58 \pm 0.11 \text { for AML }\end{array}$ \\
\hline F4 & $122.1 \pm 1.31$ & $-20.24 \pm 0.20$ & $0.104 \pm 0.08$ & $\begin{array}{c}79.35 \pm 0.13 \text { for VAL } \\
\text { F5 }\end{array}$ \\
\hline F5 & $130.1 \pm 1.30$ & $-20.45 \pm 0.24$ & $0.098 \pm 0.02$ & $80.02 \pm 0.16$ for VAL \\
& & & & $60.01 \pm 0.14$ for AML \\
\hline F6 & $152.7 \pm 1.29$ & $-23.45 \pm 0.33$ & $0.097 \pm 0.06$ & $81.12 \pm 0.12$ for VAL \\
& & & & $60.83 \pm 0.16$ for AML \\
\hline
\end{tabular}

Table 2

CHARACTERISTICS OF PLGA NPS WITH A MIXTURE OF CARDIOVASCULAR APIS ENCAPSULATED 
table 2. By increasing of stirring speed, the particle size of NPs was decreased from F1 (PLGA: $17 \mathrm{mg}, 1200 \mathrm{rpm}$ ): $158.4 \pm 1.15 \mathrm{~nm}$ to F4 (PLGA: $17 \mathrm{mg}, 2400 \mathrm{rpm}$ ): $122.1 \pm$ $1.3 \mathrm{~nm}$, from F2 (PLGA: $34 \mathrm{mg}, 1200 \mathrm{rpm}$ ): $171.1 \pm 1.30$ $\mathrm{nm}$ to F5 (PLGA:34 mg, $2400 \mathrm{rpm}$ ): $130.1 \pm 1.30$, from F3 (PLGA: $51 \mathrm{rpm}, 1200 \mathrm{rpm}$ ): $204.1 \pm 1.34 \mathrm{~nm}$ to F6 (PLGA: $51 \mathrm{rpm}, 2400 \mathrm{rpm}$ ): $152.7 \pm 1.29 \mathrm{~nm}$. Increasing the stirring speed resulted in the formation of smaller particles. Moreover, as the content of PLGA was increased, the particle size of NPs was also increased; at $1200 \mathrm{rpm}$ from F1 (PLGA $17 \mathrm{mg}$ ) $158.4 \pm 1.15 \mathrm{~nm}$ to F3 (PLGA 51 $\mathrm{mg}) 204.1 \pm 1.34 \mathrm{~nm}$, and at $2400 \mathrm{rpm}$ from F4 (PLGA: 17 $\mathrm{mg}, 2400 \mathrm{rpm}$ ): $122.1 \pm 1.3 \mathrm{~nm}$ to F6 (PLGA: $51 \mathrm{rpm}, 2400$ rpm): $152.7 \pm 1.29 \mathrm{~nm}$. The particle size increased with the increasing of PLGA concentration was also reported in literature [16]. As the concentration of PLGA increases, the viscosity of the nanosuspension increases proportionally; thereby these phenomena lead to an increase in the size of the nanoparticles [16]. Particle size represents a critical factor for drug delivery systems as nanoparticles; it influences the circulating half-life, biodistribution, cellular uptake and the drug's release kinetics (the smaller the particle size, the faster the release rate) [17].

The effect of PLGA concentration on particle size can be explained by the viscosity of the organic phase, as well as the presence of number of polymer chains per unit volume of organic solvent [18]. Increasing PLGA concentration leads to an increased of the organic solution viscosity and therefore, the diffusion of the organic solvent into the aqueous phase is slowed down, forming larger droplets, which in turn provide larger nanoparticles [19]. Furthermore, Song X. et al. demonstrated that higher PLGA concentration favors some polymer-polymer interactions, thus more polymer chains remain associated during the solvent's diffusion into the aqueous medium [17].

Polydispersity indices were low and showed little variability between different samples, ranging from 0.048 \pm 0.03 to $0.104 \pm 0.08$. The values of PDI had no significant differences no matter what concentration of PLGA or stirring speed were used in the preparation. All six samples show ed a PDI less than 0.15 , which means a significantly higher homogeneity of the systems. For all six formulations, the electric charge was negative, which could be due to the terminal carboxylic groups of PLGA present on the surface of the nanoparticles [20]. The zeta potential ranged between $-13.46 \pm 0.31 \mathrm{mV}$ and $-23.45 \pm 0.33 \mathrm{mV}$, and according to literature [20], all samples indicated a moderate stability. With the increasing of the amount of PLGA, the NPs had became more and more turbid and the $æ$ æ-potential becoming more and more negative. Dinh, Tran et al. demonstrated that PLGA NPs showed a significant reduction in æ-potential related to the poloxamer coating on NPs surface of Pluronic F127 which reduced the electrophoretic mobility [20].

\section{Conclusions}

In this study, we have demonstrated that the AML-VALPLGA NPs represent promising dual-drug delivery systems for encapsulating poorly water-soluble drugs as combined therapy in cardiovascular disease. All six formulations had significant encapsulation efficiency ( $\mathrm{EE}, \%): 79.89 \pm 0.13$ $-81.12 \pm 0.12 \%$ for VAL and $58.90 \pm 0.12-67.58 \pm 0.11$ for $A M L \%$ for AML. According to this characteristic and depending of the two variable parameters (PLGA concentration and stirring speed), the bestformulation was F6 (AML:VAL:PLGA = 1:16:51 w/w, $2400 \mathrm{rpm}$ ). AML-VAL NPs with mean particle size about $122.1 \pm 1.31$ to $204.1 \pm$ $1.34 \mathrm{~nm}$ were successfully prepared by nanoprecipitation method. All nanoformulations showed a negative æpotential ranging between $-13.46 \pm 0.31 \mathrm{mV}$ and $-23.45 \pm$ $0.33 \mathrm{mV}$, indicating a moderate stability, and a PDI values smaller than 0.15 , which means a significantly higher homogeneity of the systems. These data reveal that amlodipine besylate and valsartan encapsulated in PLGA NPs could be used as nano-therapeutic delivery systems in combined therapy for cardiovascular disease's treatment. However, further in vitro studies are needed to demonstrate the pharmacokinetic and pharmacodynamic effect.

Acknowledgement: This work was financial supported by Romanian National Authority for Scientific Research - ANCSI through Contract 6N/2016- PN 1627-02-01.

\section{References}

1.MITCHELI, G.F., Artery Res, 3, no. 2, 2009, p. 56-64.

2. DOADRIO, A.L., SANCHEZ-MONTERO, J.M., DOADRIO, J.C., SALINAS, A.J .,VALLET-REGI, M., Eur. J. Pharm. Sci., 97, 2017, p. 1-8.

3. RIVIS, A., HADARUGA, N.G., HADARUGA, D.I., TRASCA, T., DRUGA, M., PINZARU, I., Rev. Chim. (Bucharest), 59, no.2, 2008, p. 149

4. PAVALOIU, R-D., STOICA-GUZUN, A., STROESCU, M., DOBRE, T., Rev. Chim. (Bucharest), 65, no.7, 2014, p. 852

5. EMERICH, D.F., THANOS, C.G., J. Drug. Target., 15, no. 3, 2007, p. 163-183.

6. ESHEL-GREEN, T., BIANCO-PELED, H., Colloids Surf. B Biointerfaces, 139, 2016, p. 42-51.

7. ALMOUSTAFA, H.A., ALSHAWSH, M.A., CHIK, Z., Int. J. Pharm., 533, no. 1, 2017, p. 275-284.

8. ZHANG, F., Front. Chem., 5, 2017, p. 80.

9. ALVAREZ-VARGAS, M.L., GALVEZ-OLORTEGUI, J.K., GALVEZOLORTEGUI, T.V., SOSA-ROSADO, J.M., CAMACHO-SAAVEDRA, L.A., Medwave, 15, no. 9, 2015, p. 6290.

10.GRIFFIN, B.R., SCHINSTOCK, C.A., Mayo. Clin. Proc., 90, no. 2, 2015, p. 273-279.

11.GOLDBERG, D., ALEMAYEHU, D., KOURY, K., Arch. Intern. Med., 154, no. 13, 1994, p. 1461-1468.

12. FALKNER, B., Am. J. Hypertens., 31, no.1, 2017, p. 18-20.

13. MAKADIA, H.K., SIEGEL, S.J., Polymers (Basel), 3, no. 3, 2011, p. 1377-1397.

14. KUMAR, M.N.V.R., BAKOWSKY, U., LEHR, C.M., Biomaterials, 25, 2004, p. 1771-1777.

15. KHERADMANDNIA, S., VASHEGHANI-FARAHANI, E., NOSRATI, M., ATYABI, F., Iran J. Chem. Chem. Eng., 29, no. 4, 2010, p.181-187.

16. CHEN, Y. C., HSIEH, W. Y., LEE, W. F., ZENG, D. T., J Biomate.r Appl., 27, no.7, 2013, p. 909-922.

17. ZHANG, C., GU, C., PENG, F., LIU, W., WAN, J., XU, H., LAM, C.W., YANG, X., Molecules, 18, 2013, p. 13340-13356.

18. SONG, X., ZHAO, Y., HOU, S., XU, F., ZHAO, R., HE, J., CAI, Z., LI, Y., CHEN, Q., Eur. J. Pharm. Biopharm., 69, 2008, p. 445-453.

19. DOS SANTOS, K.C., DA SILVA, M.F.G.F., PEREIRA-FILHO, E.R., FERNANDES, J.B., POLIKARPOV, I., FORIM, M.R., Nanotechnol Sci. Appl., 5, 2012, p. 37-48.

20. CLOGSTON, J. D. and PATRI, A. K., Methods Mol. Biol., 697, 2011, p. 63-70.

$\overline{\text { Manuscript received: } 5.11 .2017}$ 